\title{
The Correlation between Inclination and the Thickness of Maxillary Central Incisors at Orthodontic Clinic of RSGM FKG USU (Research Report)
}

\author{
Nurhayati \\ Orthodontic Department \\ Faculty of Dentistry, Universitas Sumatera Utara \\ Medan, Indonesia \\ drgnurhayati@yahoo.co.id
}

\author{
Amalia Oeripto \\ Orthodontic Department \\ Faculty of Dentistry, Universitas Sumatera Utara \\ Medan, Indonesia
}

\begin{abstract}
In an orthodontic treatment, the labio-lingual movement of the anterior teeth is required to improve the sagittal relationship of the maxillary and mandibular arch in order to achieve a more harmonious profile. However, excessive force to the teeth movement could lead to iatrogenic effect, therefore an evaluation of tooth supporting tissue is essential prior to treatment. The purpose of this research is to understand the relationship between inclination and the thickness of the alveolar bone of the maxillary central incisors. The total sample in this research is $\mathbf{1 3 5}$ lateral cephalograms, divided into three groups: normal inclination, proclination and retroclination respectively. The labio-lingual inclination of the central incisors is determined based on the angle of central maxillary incisor towards Sella-Nasion (SN Plane). The labial and lingual thickness of the alveolar bone is determined by a line drawn perpendicular to the axis of the tooth, measured in linear on each 1/10 level along the root of teeth, from cement-enamel junction until the root of apical the central maxillary incisor. Kruska-Wallis test is used to determine the relationship between the inclination and the alveolar bone thickness of central maxillary incisors. There is a significant difference between the thickness of the labial and lingual alveolar bone with the inclination $(p<0.005)$. There is a significant relationship between the inclination of the alveolar bone thickness with labial and lingual root apical teeth on central maxillary incisive. The retroclined central maxillary teeth tend to have thinner labial alveolar bone support especially in root area and must be taken into consideration. The prevalence of fenestration in retroclined is higher than normal group and there was no fenestration in proclined group.
\end{abstract}

Keywords-central maxillary incisors inclination, alveolar bone thickness, lateral cephalometry, fenestration

\section{INTRODUCTION}

Alveolar bone is a part of maxillary and mandibular forming and supporting bony socket of tooth (alveoli). This bone is formed when tooth erupts to provide space for periodontal ligament, but will gradually disappear when tooth is extracted. Solid cortical plate on root apical of labial and lingual incisor teeth is considered as orthodontic wall and is an anatomical boundary of teeth movement during their reposition. Ten Hoeve and Mulie claimed that there is no anatomical boundary of teeth movement in area of alveolar bone margin and that there is anatomical boundary in root apical since root apical is adjacent to palatal cortical bone. In orthodontic treatments, it is necessary to have labiallingual movement of anterior teeth to fix sagittal relationship of maxillary and mandibular arch to achieve a more harmonious patient profile. However, excessive teeth movement may result in iatrogenic symptoms of teeth supporting tissue such as external root resorption, dehiscence, fenestration, and gingival recession. Apart from aesthetical view, periodontal health and alveolar bone boundaries are important factors in orthodontic treatments. Isolated area where roots are not covered by alveolar bone and their surfaces are only covered by periosteum and gingiva overlying is called fenestration. Meanwhile lack of labial or lingual cortical plate which results in exposure of the surface of cervical root and affects marginal bones induces alveolar disorder called dehiscence.

\section{MATERIALS AND METHODS}

Tools employed in this research are tracing box, $4 \mathrm{H}$ pencils, tapes, ruler, digital caliper and eraser, protractor (Ormco), scanner (Canon Scan Lide 100), and AutoCAD 2007 software used to measure thickness of alveolar bones. Materials used are maxillary study model, lateral cephalometry images, and tracing paper. Method of research is by taking sample of maxillary study model using criteria crowded $<\mathrm{mm}$ and diastema $<1 \mathrm{~mm}$. Teeth inclination is measured based on maxillary central incisor angle toward Sella-Nasion (SN) area. Proclined: $\left(105-120^{0}\right)$, normal: $\left(100-104^{0}\right)$, retroclined: $\left(84-99^{0}\right)$. Length of root is determined by measuring distance between CEJ to apical and divided into 10 levels by the same long sagittal cut chosen, level 0 represents cement enamel junction/CEJ and level 10 represents root apical. Thickness of labial and lingual alveolar bone is determined by a line drawn perpendicular to axis of tooth, measured in linear on 
each 1/10 level along root of teeth, from cement-enamel junction to root apical of central maxillary incisor.

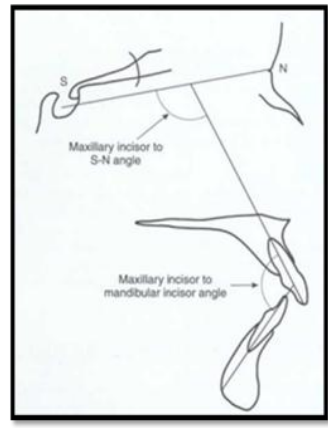

Figure 1. Maxillary incisor to $\mathrm{S}-\mathrm{N}$ angle $(\mathrm{I}-\mathrm{SN})$ relates to axial inclination of the most labial maxillary incisor via a line through anterior cranium bases [4].

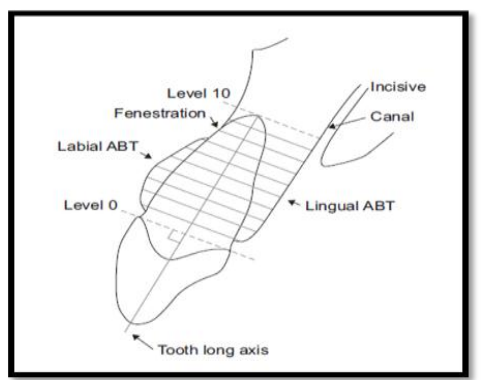

Figure 2. Illustration scheme of measurement of the thickness of labial and lingual bones. Level 0 , cement to enamel junction; level 10, root apical area, $\mathrm{ABT}=\mathrm{alveolar}$ bone thickness [3].

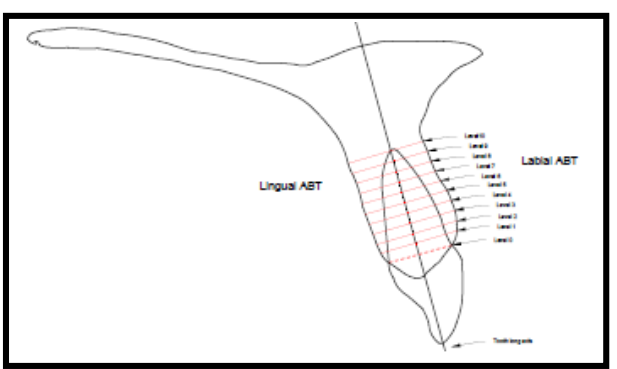

Figure 3. Outline of the thickness of alveolar and labial bones every $1 / 10$ level.

\section{RESULTS}

In this research normal group $\left(100-104^{0}\right)$ samples are 45 comprising 9 males and 36 females whose average age is $20,93 \pm 3,43$, the youngest of which is 18 years old and the oldest is 32 years old. Proclined group $\left(105-120^{\circ}\right)$ samples are 45 consisting of 6 males and 39 females whose average age is $20,33 \pm 2,89$, the youngest of which is 18 years old and the oldest is 30 years old. Retroclined group (84-99 $)$ samples are 45 consisting of 14 males and 31 females, the youngest of which is 18 years old and the oldest is 34 years old.

TABLE I. THE DISTRIBUTION OF ANGLE IN MAXILLARY CENTRAL INCISOR INCLINATION GROUP

\begin{tabular}{|l|c|c|c|c|}
\hline \multirow{2}{*}{ Inclination } & \multicolumn{4}{|c|}{ Angle of central maxillary incisor inclination } \\
\cline { 2 - 5 } & $\mathbf{X}\left({ }^{\mathbf{0}}\right)$ & SD & $\operatorname{Min}\left({ }^{\mathbf{0}}\right)$ & $\operatorname{Max}\left({ }^{\mathbf{0}}\right)$ \\
\hline Normal & 102.38 & 1.72 & 100.00 & 104.00 \\
\hline Proclined & 112.82 & 4.32 & 105.00 & 120.00 \\
\hline Retroclined & 96.64 & 11.89 & 87.00 & 99.00 \\
\hline
\end{tabular}

Table I shows that the average value and standard deviation in normal inclination group is $102.38 \pm 1.72$ with the smallest angle is 100.00 and the biggest is 104.00. The average value and deviation standard for proclined group is $112.82 \pm 4.32$ with the smallest angle is 105.00 and the biggest is 120.00. In retroclined group, the average value and deviation standard is 96.64 \pm 11.89 with the smallest angle is 87.00 and the biggest is 99.00

TABLE II. THE DIFFERENCE OF LABIAL ALVEOLAR BONE THICKNESS OF MAXILLARY CENTRAL INCISOR

\begin{tabular}{|c|c|c|c|c|c|c|c|}
\hline & \multicolumn{9}{|c|}{ The thickness of alveolar bone of central } & \\
maxillary incisor & \multicolumn{2}{c|}{$\begin{array}{c}\text { Proclined } \\
\text { Level }\end{array}$} & $\begin{array}{c}\text { Normal } \\
\text { Inclination }\end{array}$ & \multicolumn{2}{c|}{$\begin{array}{c}\text { Retroclined } \\
\text { Inclination }\end{array}$} & \multicolumn{2}{c|}{$\begin{array}{c}\text { Inclination } \\
\text { value }\end{array}$} \\
\cline { 2 - 7 } & $\begin{array}{c}\mathbf{X} \\
(\mathbf{m m})\end{array}$ & SD & $\begin{array}{c}\mathbf{X} \\
(\mathbf{m m})\end{array}$ & SD & $\begin{array}{c}\mathbf{X} \\
(\mathbf{m m})\end{array}$ & SD & \\
\hline 1 & 0.91 & 0.65 & 0.76 & 0.51 & 1.07 & 0.66 & .079 \\
\hline 2 & 1.10 & 0.55 & 0.96 & 0.54 & 1.18 & 0.59 & .371 \\
\hline 3 & 1.04 & 0.47 & 1.08 & 0.48 & 1.15 & 0.50 & .690 \\
\hline 4 & 1.22 & 1.34 & 1.17 & 0.45 & 1.08 & 0.55 & .169 \\
\hline 5 & 1.07 & 0.57 & 1.37 & 0.58 & 1.02 & 0.59 & .005 \\
\hline 6 & 1.37 & 1.05 & 1.56 & 0.67 & 0.92 & 0.66 & .000 \\
\hline 7 & 1.60 & 0.89 & 2.07 & 1.03 & 0.92 & 0.79 & .000 \\
\hline 8 & 2.15 & 1.10 & 2.73 & 1.12 & 1.20 & 1.13 & .000 \\
\hline 9 & 3.04 & 1.42 & 3.70 & 1.58 & 1.84 & 1.35 & .000 \\
\hline 10 & 5.13 & 1.95 & 5.75 & 2.22 & 3.63 & 1.97 & .000 \\
\hline
\end{tabular}

Table 2 shows the difference of average values and standard deviation of each level for every group based on the thickness of labial alveolar bone. Numerical data display that level 1 to level 5 show no statistically significant difference of labial alveolar bone thickness for every inclination group where $p>0.05$. Level 6 to level 10 show significant different of labial alveolar bone thickness for every inclination group where $\mathrm{p}=0.00, \mathrm{p}<0.05$. The thickest labial alveolar bone of root apical is found in proclined group which is $5.75 \pm 2.22$, and is followed by normal group which is $5.13 \pm 1.95$, whereas the least can be seen in retroclined group which is $3.63 \pm 1.97$.

TABLE III. THE DIFFERENCE OF LINGUAL ALVEOLAR THICKNESS OF MAXILLARY CENTRAL INCISOR

\begin{tabular}{|c|c|c|c|c|c|c|c|}
\hline \multirow{3}{*}{ Level } & \multicolumn{6}{|c|}{$\begin{array}{c}\text { Alveolar Bone Thickness of Maxillry Central } \\
\text { Incisor }\end{array}$} & \multirow{3}{*}{$\begin{array}{c}\mathbf{p} \\
\text { value }\end{array}$} \\
\hline & \multicolumn{2}{|c|}{$\begin{array}{c}\text { Normal } \\
\text { Inclination }\end{array}$} & \multicolumn{2}{|c|}{$\begin{array}{l}\text { Proclined } \\
\text { Inclination }\end{array}$} & \multicolumn{2}{|c|}{$\begin{array}{l}\text { Retroclined } \\
\text { Inclination }\end{array}$} & \\
\hline & $\begin{array}{c}\mathbf{X} \\
(\mathbf{m m})\end{array}$ & SD & $\begin{array}{c}\mathbf{X} \\
(\mathbf{m m})\end{array}$ & SD & $\underset{(\mathbf{m m})}{\mathbf{X}}$ & SD & \\
\hline 1 & 0.75 & 0.58 & 0.44 & 0.42 & 0.59 & 0.45 & .110 \\
\hline 2 & 1.02 & 0.57 & 0.94 & 0.68 & 1.16 & 0.99 & .806 \\
\hline 3 & 1.39 & 0.56 & 1.44 & 0.64 & 1.77 & 0.88 & .141 \\
\hline 4 & 1.84 & 0.63 & 1.82 & 0.73 & 2.42 & 1.14 & .050 \\
\hline 5 & 2.38 & 0.80 & 2.30 & 0.89 & 3.22 & 1.24 & .000 \\
\hline 6 & 2.83 & 1.04 & 2.84 & 1.00 & 3.86 & 1.24 & .000 \\
\hline 7 & 3.51 & 1.02 & 3.34 & 1.08 & 4.80 & 1.36 & .000 \\
\hline 8 & 4.29 & 1.32 & 4.07 & 1.25 & 5.59 & 1.54 & .000 \\
\hline 9 & 5.19 & 1.47 & 4.72 & 1.40 & 6.81 & 1.73 & .000 \\
\hline 10 & 7.13 & 1.74 & 6.73 & 1.39 & 11.08 & 1.71 & .000 \\
\hline
\end{tabular}

Table III shows the difference of average value and standard deviation for each group based on the lingual alveolar bone thickness. The lingual alveolar bone 
thickness gradually increased from cement enamel junction to root apical. Level 1 to level 4 show no significant difference in the lingual alveolar bone thickness where $p>0.05$. Meanwhile level 5 to 10 statistically show significant difference in the lingual alveolar bone thickness where $\mathrm{p}=0.00, \mathrm{p}<0.05$. Numerical data also show that lingual alveolar bone is the thickest in retroclined group which is $11.08 \pm 1.71$, and is followed by normal group that is $7.13 \pm 1.74$. The least is shown by proclined group that is $6.73 \pm 1.39$.

TABLE IV. THE CORRELATION BETWEEN INCLINATION AND THE THICKNESS OF LABIAL AND LINGUAL ALVEOLAR BONES IN ROOT APICAL OF MAXILLARY CENTRAL INCISOR

\begin{tabular}{|c|c|c|c|c|c|c|c|}
\hline \multirow{3}{*}{$\begin{array}{l}\text { Alveolar } \\
\text { bone }\end{array}$} & \multicolumn{6}{|c|}{$\begin{array}{c}\text { The thickness of alveolar bone in the root apical of } \\
\text { maxillary central incisor }\end{array}$} & \multirow{3}{*}{$\begin{array}{c}\mathbf{P} \\
\text { value }\end{array}$} \\
\hline & \multicolumn{2}{|c|}{ Normal } & \multicolumn{2}{|c|}{ Proclined } & \multicolumn{2}{|c|}{ Retroclined } & \\
\hline & $\underset{(\mathbf{m m})}{\mathbf{X}}$ & SD & $\underset{(\mathbf{m m})}{\mathbf{X}}$ & SD & $\begin{array}{c}\mathbf{X} \\
(\mathbf{m m})\end{array}$ & SD & \\
\hline Lingual & 7.13 & 1.74 & 6.73 & 1.39 & 11.08 & 10.71 & .000 \\
\hline Labial & 5.13 & 1.95 & 5.75 & 2.22 & 3.63 & 1.97 & .000 \\
\hline
\end{tabular}

Table IV shows the correlation between inclination and the thickness of labial and lingual alveolar bones in the root apical. The numeric data explains that there is significant relationship between inclination and the thickness of labial and lingual alveolar bones in the root apical where $\mathrm{p}=0.00, \mathrm{p}<0.05$.

TABLE V. THE CORRELATION BETWEEN INCLINATION AND ALVEOLAR BONE FENESTRATION IN TEETH ROOT OF MAXILLARY CENTRAL INCISOR

\begin{tabular}{|l|c|c|c|c|}
\hline \multirow{2}{*}{ Fenestration } & \multicolumn{3}{|c|}{$\begin{array}{c}\text { The inclination of maxillary } \\
\text { central incisor }\end{array}$} & $\begin{array}{c}\text { P } \\
\text { value }\end{array}$ \\
\cline { 2 - 4 } & Normal & Retroclined & Proclined & \\
\hline Positive & 2 & 13 & 0 & \multirow{2}{*}{$0.002 *$} \\
\hline Negative & 43 & 32 & 0 & \\
\hline Sum & 45 & 45 & 0 & *significant $<0.05, *$ Kruskal Wallis test \\
\hline
\end{tabular}

Table $\mathrm{V}$ shows that fenestration on the surface of alveolar bone in teeth root of maxillary central incisor are 13 samples in retroclined group and 2 samples in normal group, while proclined group shows no fenestration. Fenestration is more common in retroclined group and more often takes place in the labial alveolar bone. This table shows that there is a significant correlation between teeth inclination and alveolar bone fenestration where $\mathrm{p}<0.05$.

This research also demonstrates that $90 \%$ of the normal group and $80 \%$ of the retroclined group correlate negatively to the alveolar bone thickness in each level. Proclined group shows $60 \%$ positive correlation to alveolar bone thickness in every level.

\section{DISCUSSION}

This study is an observational research employing case series method to identify the correlation between inclination and the thickness of labial and lingual alveolar bone in maxillary central incisor. Subjects of this research are patients coming to RSGMP clinic at FKG USU aged 18-35 years old who have never had orthodontic treatment. The samples are their maxillary central incisor teeth.

A thorough measurement of the thickness of alveolar bone of maxillary central incisor can aid an orthodontist to diagnose and plan the proper treatment to intensify the result. The movement of labial-lingual anterior teeth to increase the relationship between sagittal arch and maxillary mandibular is required in order to achieve harmonious profile. However, excessive teeth movement may result in iatrogenic symptoms including root resorption, gingiva recession, and alveolar bone loss. Apart from aesthetic value, periodontal health and alveolar bone boundaries are important factors in orthodontic treatment.

This research shows that there is a significant correlation between inclination and the thickness of labial and lingual alveolar bone in root apical of maxillary central incisor. The result can be seen in table 4 where $p=0.00, p<0.05$. This finding confirms the previous study conducted by Zhou et al.

The finding that retroclined maxillary central incisor teeth tend to have thinner labial bone support, especially in root apical area, shows that patients with retroclined incisor teeth need to be carefully treated. The orthodontist must very carefully decide whether to have conventional orthodontic treatment or combined orthodontic treatment in patients who have protruded maxillary with retroclined incisor teeth compensation. If compensated orthodontic is selected for patients with little skeletal discrepancy, the orthodontist must ensure efforts to control anterior teeth jaw torque and to achieve control of root movement. The appropriate teeth torque is also essential to achieve better occlusion, face aesthetics, and stability. Complications may occur if torque is not controlled as expected. In this research, the thickness of labial alveolar bone in maxillary central incisor of retroclined group is $3.63 \pm 1.97$ and is the smallest number of bone thickness.

The finding of this research shows that incisor teeth in retroclined group have bigger fenestration prevalence which is 13 teeth and dominant fenestrations take place on surface of labial root. Next in line is the normal group with 2 teeth. This finding confirms that of Lou et al. previous study. After fenestration takes place, cortical plate is penetrated, and restoration of perforated area is no longer possible unless there is tooth relapse. Therefore, it is necessary to have thorough evaluation of periodontal bone support in patients with retroclined incisor teeth. Fenestration prior to treatment must be identified, and patients must be informed about escalation of worse periodontal damage risk.

Finding of this research also shows that proclined maxillary central incisor teeth have thicker labial bone in area of root apical that is 5.75 \pm 2.22 . Patients who have protruded maxillary dentoalveolar with anterior teeth flaring possess bigger volume of bone support that enables posterior teeth extractions followed by some tipping movements. Several researchers argue that teeth movement during extraction is not pure transformation but is movement combination of tipping. Extractions 
result in incisor teeth being in a line with basal bone and ensure long digital capillary stability. Thus, compared to retroclined central incisor teeth, proclined incisor teeth movements are relatively simple and secure [8]. Thickness of labial alveolar bone in root apical of proclined group is $5.75 \pm 2.22$ and that of lingual bone is $6.73 \pm 1.35$. On the other hand, thickness of labial alveolar bone in root apical of retroclined group is $3.63 \pm 1.97$ and the lingual bone is $11.08 \pm 1.71$.

This research also shows that alveolar bone in the marginal area is thin. Some studies have proven that orthodontic treatment may result in the loss of marginal alveolar bone and gingiva recession. Other researchers state that the loss of alveolar bone is more visible in the marginal areas. This is due to the fact that movements in the area are mostly controlled by tipping, and retraction force onto incisor teeth is concentrated in the crest alveolar, which leads to bigger pressure accumulation in marginal areas.

Normal inclined group has $90 \%$ negative correlation where the smaller the inclination angle is the thicker alveolar bone is. Proclined group is $60 \%$ positively correlated which means that the bigger the inclination angle is the thicker the alveolar bone is. Meanwhile the retroclined group has $80 \%$ negative correlation in which the smaller the inclination angle is the thicker the alveolar bone is.

The thickness of alveolar lingual bone gradually increases from cement enamel junction to the root apical. There is a significant difference between the thickness of labial alveolar and lingual bone in different inclination. This research also shows significant correlation between inclination and the thickness of labial and lingual alveolar bone in the root apical.

This study shows that maxillary central incisor teeth of the retroclined group have bigger fenestration prevalence and the dominant fenestration takes place on the surface of labial root. There is also significant correlation between teeth inclination and fenestration.

Retroclined maxillary central incisor teeth tend to have thinner labial bone support, especially in the labial root apical. This shows that patients with retroclined incisor teeth must be carefully treated. The finding also shows that proclined maxillary central incisor teeth have thicker labial bone in the root apical area so that it is safer for teeth movement. Therefore, compared to the movement of retroclined central incisor teeth, that of proclined incisor teeth is relatively more simple and secure.

Further research employing CBCT are necessary because this device can generate clearer outline images of alveolar bone anatomical boundaries of maxillary central incisor teeth. More research with more samples is also recommended to obtain better results.

\section{REFERENCES}

[1] C.S. Handelman, "The anterior alveolus: Its importance in limiting orthodontic treatment and its influence on the occurrence of iatrogenic sequelae," Angle Orthod. J., vol. 66(2), pp. 95-110, 1996.
[2] A. Yagci, I. Veli, T. Uysai, F.I. Ucar, T. Ozer, S. Enhos, "Dehiscence and fenestration in skeletal class I, II, and III malocclusions assessed with cone-beam computed tomography," Angle Orthod. J., vol. 82(1), pp. 67-74, 2012.

[3] Y. Tian, F. Liu, H.J. Sun, P. Lv, Y.M. Cao, M. Yu, Y. Yue, "Alveolar bone thickness around maxillary central incisor of different inclination assessed with cone-beam computed tomography," The Korean J. of Orthodontics, vol. 45, pp. 245 252, 2015.

[4] W. Ardhana. Hubungan antara pengukuran inklinasi gigi insisivus sentralis secara linier pada model studi dengan pengukuran secara angular pada sefalometri lateral Wayanardhana. Available: staff.ugm.ac.id/publikasi_3.htm.

[5] A. Jacobson, Radiographic cephalometry. Chicago: Quintessence Publishing Co. 2006.

[6] L.F. Andrew. "The six key to normal occlusion. Am. J. Orthod. Dentofacial Orthop., pp. 296-309, 1972.

[7] P.S. Pudyani, D. Susantyo, S. Suparwitri. "Morphological change of alveolar bone due to orthodontic movement of maxillary and mandibular incisors," Dent. J. (Maj. Ked. Gigi), vol. 41, pp. 21-24, 2008.

[8] D.G. Garib, M.S. Yatabe, T.O. Ozawa, O. Gabriel, S. Filho, "Alveolar bone morphology under perspective of the computed tomography: Defining the biological limits of tooth movement," Dental Press J. Orthod., vol. 15(5), pp. 192-205, 2010.

[9] W.R. Proffit, Contemporary orthodontics, $4^{\text {th }}$ ed., St. Louis: CV Mosby Co. 2007, pp. 351-252

[10] S. Enhos, T. Uysai, A. Yagci, I. Veli, F.I. Ucar, T. Ozer "Dehiscence and fenestration in patient with different vertical growth patterns assessed with cone-beam computed tomography,” Angle J. Orthod., vol. 82(5), pp. 868-874, 2012.

[11] J.M. Limas-Careras, A. Amarila, E. Espinar-Escalona, L. Catelanos-Cosano, J. Martin-Gonzales, B. Sances-Domingues, F.J. Lopes-Fries, "External apical root resorption in maxillary root filled incisor after orthodontic treatment: A split-mouth design study,” Med. J. Oral Patol., vol. 117(3), pp. e523-527, 2012

[12] H. Mohandesan, H. Ravanmehr, N. Valaei, "A radiographic analysis of external apical root resorption of maxillary incisors during active orthodontic treatment," Europ. J. Orthod., vol. 29, pp. 134-9, 2007.

[13] S.E. Bishara. Textbook of orthodontics. W.B. Saunders Company, 2001, pp. 463.

[14] M. Khalifa, "Bone fenestration: A case report of management of a lower anterior buccal bone fenestration," International Dental J. of Students Research, vol. 3(2), pp. 49-51, 2015.

[15] C.L. Quaglio, K.M.S. Freitas, M.R. Freitas, G. Janson, J.F.C Henriques, "Stability of maxillary anterior crowding treatment," Dental Press J. Orthod., vol. 17(4), pp. 57-64, 2012.

[16] R.M. Little, "The irregularity index: A quantitative score of mandibular anterior alignment," Am. J. Orthod. Dentofacial Orthop., vol. 68(5), pp. 554-563, 1975.

[17] B.S. Iyyer, S.I. Bhalajhi, "Orthodontics the art and science," $3^{\text {rd }}$ ed., New Delhi: Arya Medi, 2006, pp. 184.

[18] A.S. Wahyuni. Statistika kedokteran, Bamboedoea Communication, pp. 35-45, 51-67.

[19] S.H. Dalimunte, Periodonsia, Departemen Periodonsia Fakultas Kedokteran Gigi Universitas Sumatera Utara, 2008, pp. 32-39. 